\title{
REVISIONARY NOTES ON THE SANGUINEA AND NEOGAGATES GROUPS OF THE ANT GENUS FORMICA ${ }^{1}$
}

By E. O. Wilson and W. L. Brown, JR.

\section{Harvard University}

In recent years, specialists engaged in ecological and regional studies of North American ants have repeatedly called upon us to check species identification against types and other "historic" material in the Museum of Comparative Zoology (MCZ). The specialist working away from such a collection is likely to assume that the difficulty can readily be cleared up by mere comparison of his fresh material against the Museum series; unfortunately, such comparison by itself rarely produces satisfactory results. Of the groups arriving at the $\mathrm{MCZ}$, one causing repeated difficulty is the so-called subgenus Raptiformica of Formica. In many ways, it exemplifies the current taxonomic conditions within many of our commonest groups of ants.

The principal fault of the accepted Raptiformica arrangement lies in an excessive unrecognized synonymy, which in turn stems from past failure to appreciate the extent of allometric and other normal expressions of intraspecific variation. Species such as pergandei and rubicunda have been founded in large part on supposed differences in head shape, but closer examination shows these and other cases to be nothing more than size variants along the same general allometric gradient. Trivial variations in pilosity, sculpturing, and color have also been much overworked in separating "species"; examination of enough material soon reveals most such variation as continuously intergradient and broadly bridging the old gaps.

Another situation bound to give continuing trouble in the future concerns the elusiveness of presumed sibling species such as $F$. parcipappa, $F$. curiosa and $F$. wheeleri-

\footnotetext{
${ }^{1}$ Published with a grant from the Museum of Comparative Zoology at Harvard College.
} 
we have been unable to find reliable and convincing characters marking the worker caste of these three forms. We are keenly aware that lack of material may have caused us to overlook other full but more or less cryptic species.

The original and present goals of this study are the elimination through synonymy of those names which cannot be supported by all available evidence, correction of certain inconsistencies in previous revisions (see literature cited at end of paper), and construction of a new key based on the present revision. After the majority of the work had been completed, however, another important consideration arose.

It had become apparent early in the task that Raptiformica included two species-groups, termed by us respectively "sanguinea complex" and "obtusopilosa complex."

The sanguinea complex is distinguished by the following assemblage of characters:

(1) The workers of all of the species usually have the gasters black and the remainder of the body red, except $F$. parcipappa, which is concolorous reddish yellow.

(2) The workers average large in size for Formica, are robust, and have a well-defined metathorax.

(3) The propodeum is short, with a well-defined angle, and the petiolar scale is high and thin.

(4) The gastric pubescence is dense and the body pilosity generally sparse. Hairs are never present on the dorsal face of the propodeum anterior to the propodeal angle.

(5) The sculpture is generally opaque, or at most rather weakly shining.

(6) The male has relatively broad parameres and a subgenital plate of a particular conformation (figs. 3, 5).

(7) All of the species take slaves, at least facultatively, except $F$. parcipappa, which is known only from limited cabinet material.

(8) The complex as a whole prefers mesic habitats. 
The obtusopilosa complex, perhaps wrongly named at the outset because obtusopilosa is the least typical and most poorly known of the species, offers the following characters :

(1) The worker coloration shows much interspecific variation, ranging from concolorous yellowish red to concolorous black or red and black.

(2) The workers average smaller in size than in the sanguinea complex, are more slender in body form, and have a poorly defined metanotum.

(3) The propodeum is proportionately longer and more rounded, with little or no angle between dorsum and declivity.

(4) The gastric pubescence is very sparse (except in obtusopilosa) and the body pilosity generally abundant. Hairs are usually present, and often abundant, on the dorsal face of the propodeum anterior to the propodeal angle.

(5) The sculpture is usually feeble and the integument therefore more shining.

(6) The male has relatively slender parameres and a subgenital plate of a distinctive conformation (figs. 4, 6).

\section{Explanation of Plate 11}

Fig. 1. Head of $F$. subintegra worker from University of Michigan Biological Station, Douglas Lake, Cheboygan Co., Mich. (P. B. Kannowski). Head width $1.71 \mathrm{~mm}$. Fig. 2. Head of putative $F$. curiosa worker from Culbertson, Roosevelt Co., Mont. (E. O. Wilson). Head width the same as in subintegra, , specimen of fig. 1. Fig. 3. Left paramere of F. subnuda male from Woodland Park, Teller Co., Colo. (W. M. Wheeler). Fig. 4. Left paramere of $F$. perpilosa male from Ft. Davis, Texas (W. M. Wheeler). Fig. 5. Posterior border of subgenital plate of same specimen as in fig. 3 ( $F$. subnuda). Fig. 6. Posterior border of subgenital plate of same specimen as in fig. 4 (F. perpilosa). Fig. 7. Left side view of petiole of $F$. subintegra worker from Rogers City, Presque Isle Co., Mich. (P. B. Kannowski). Head width $1.63 \mathrm{~mm}$. Fig. 8. Left side view of petiole of $F$. subnuda worker from Kiowa, Glacier Co., Mont. (E. O. Wilson). Head width $1.76 \mathrm{~mm}$. 

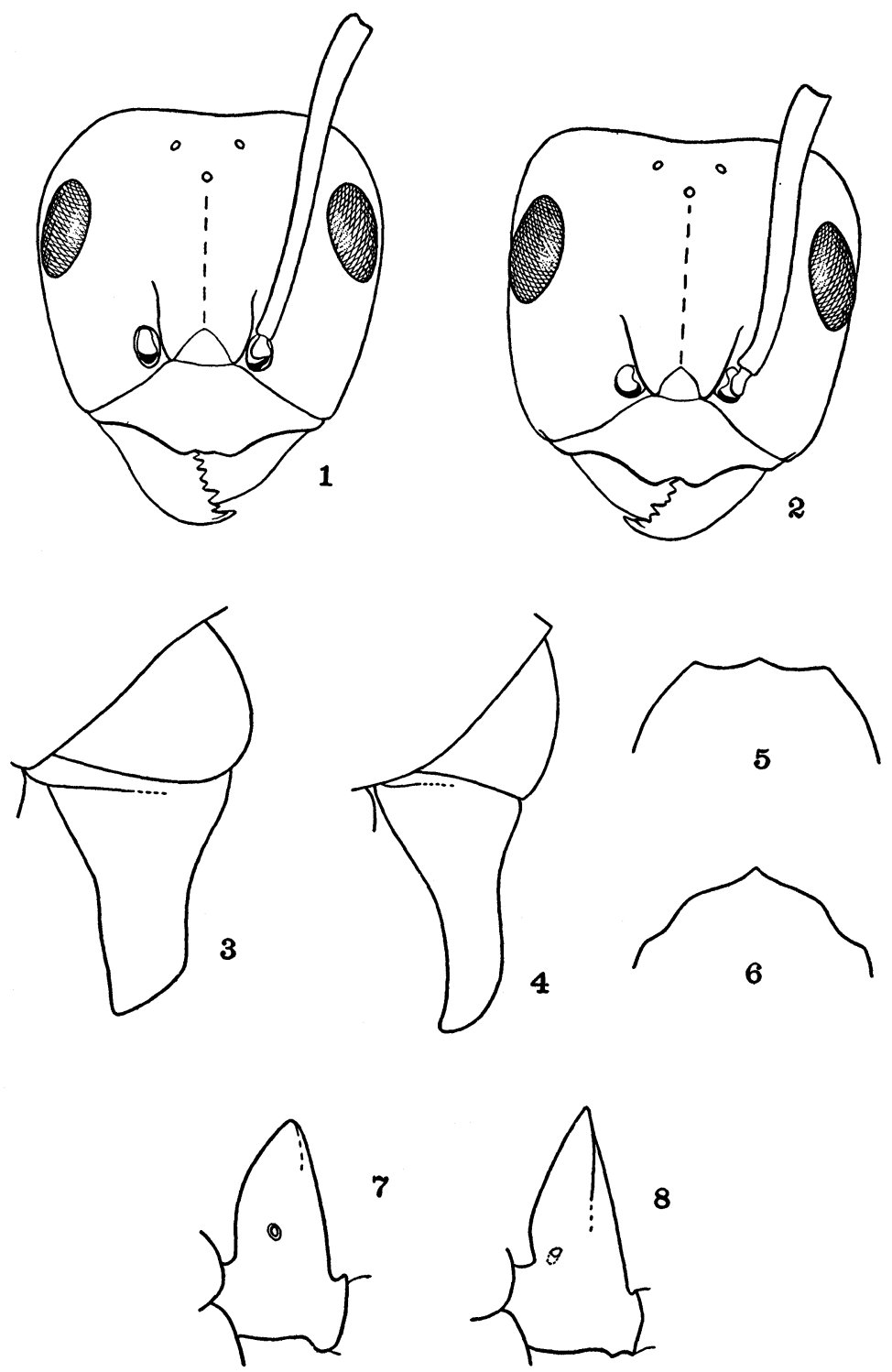

Wilson and Brown - Formica 
(7) So far as is known, none of the species ever take slaves.

(8) The complex as a whole is limited mostly to xeric habitats in western North America.

The only species placed in the obtusopilosa complex with reservations is obtusopilosa itself. In body form, pilosity, ethology, and habitat preference, it resembles the rest of the complex. But it also possesses coloration and gastric pubescence characteristic of the sanguinea complex. The male genitalia could add weighty and possibly decisive evidence, but unfortunately no obtusopilosa males seem to be available in any collection at the present time.

Both complexes share the clypeal notch character diagnostic of Raptiformica, although in general this seems better developed in the sanguinea complex. Despite the presence of the notch, we felt that the two groups were very discrete from one another, casting doubt on the validity of Raptiformica as a natural grouping. At a late moment, we were led by a chance remark by Dr. Creighton (in litt.) to reconsider certain views expressed to us in an all-but-forgotten letter received in 1953 from Dr. W. F. Buren. Buren's opinion then was that synonymy should bracket no less a pair of forms than Formica (Raptiformica) bradleyi Wheeler and Formica (Proformica) neogagates var. morbida Wheeler. Further, Buren implied that the taxonomic standing of Raptiformica and the Nearctic representatives of Proformica is due for reconsideration in the light of this synonymy ${ }^{2}$.

Checking the type material involved in this important finding, we can only agree with Buren's suggested synonymy, which certainly will have a far-reaching effect in the simplification of the taxonomy of the genus Formica. We are not prepared to enter extensively into the taxonomy of the "Proformica complex" at this time, but a few of our observations bearing on group interrelationships are offered as follows:

${ }^{2}$ See Acknowledgements at the end of this paper. 
(1) In habitus of all castes of both sexes, and in details of worker-queen sculpture, pilosity, and form of propodeum and petiole, members of the obtusopilosa complex and the Nearctic species of "Proformica" (neogagates group) are obviously similar.

(2) The diagnostic Proformica character involving proportions of the first three funicular segments, never a very happy distinction, appears to grade through in the sanguinea-obtusopilosa series.

(3) The clypeal notch, supposedly characteristic of Raptiformica, is as well (or better) developed in many $F$. neogagates specimens as it is in those of some species customarily placed in Raptiformica (e. g. bradleyi, or even subnuda). The notch in neogagates and bradleyi is more properly described as a "vaulting" of the median clypeal margin as seen from an adoral view, but the effect is the same from full-face view, and the difference from the condition of subnuda is trifling, not to say academic. In neogagates, which appears to be a species distinct from bradleyi (= morbida) on the basis of color and pilosity characters, variation in clypeal vaulting is considerable. Most western samples show stronger vaulting, frequently equalling bradleyi, while some eastern samples have a flattened border like that of lasioides.

(4) The parameres and subgenital plate of the male in neogagates, bradleyi, and perpilosa are very similar (see figs. 4,6$)$.

(5) Many of the Palaearctic species of Proformica, including the subgeneritype $F$. nasuta Nylander, differ markedly from the Nearctic species (typified by neogagates) in characters involving degree of worker polymorphism, and in worker-queen mandibular dentition. In addition, the male genitalia are very distinctive in the one species, nasuta, in which males have been examined. These species seem to form a monophyletic group easily separated from the Nearctic neogagates group as well as from all Nearctic Formica.

Conclusions drawn from these facts are: (1) the obtu- 
sopilosa complex is closest to, in fact coextensive with, the neogagates group (= Nearctic "Proformica") and probably has no direct connection with the sanguinea group; (2) the neogagates group, including the obtusopilosa complex, should be transferred to Formica s. str.; (3) unless species annectant to Formica or Cataglyphis can be demonstrated, the true Proformica of the Old World, with nasuta as its type, probably rates full generic rank; (4) the subgeneric name Raptiformica, having lost its morphological associations, should be put into synonymy until evidence is forthcoming for the need to recognize more than "species groups" in Formica.

The changes discussed in this work as they affect the old "Raptiformica" complex are outlined in the following synopsis. In this paper, only new synonymy will be cited formally; for additional synonymy and other references, see Creighton, 1950 , pp. 460-472. The treatment of the sanguinea group here together with the obtusopilosa complex no longer implies natural connection between these two assemblages of species.

curiosa Creighton

sanguinea group

parcipappa Cole

sanguinea Latreille (with "varieties")

subintegra Emery

$=$ pergandei Emery (n. syn.)

$=$ puberula Emery (n. syn.)

= rubicunda Emery (n. syn.)

= sublucida Wheeler (n. syn.)

subnuda Emery (n. status)

$=$ emeryi Wheeler (n. syn.)

wheeleri Creighton

obtusopilosa complex of neogagates group

bradleyi Wheeler

$=$ neogagates var. morbida Wheeler (n. syn., W. F.

manni Wheeler

Buren in litt.)

= oregonensis Cole (n. syn.) 


\author{
obtusopilosa Emery \\ = obtusopilosa alticola Wheeler (n. syn.) \\ perpilosa Wheeler
}

\title{
SPecies IN The Sanguinea Group Proper
}

In our study of sanguinea and relatives, we have been engaged chiefly with the Nearctic forms. It will be noticed that where Creighton recognized ten Nearctic species in the true sanguinea group, we retain only half that number, and of these five names, we can recognize only two as representing solidly verified and distinct species: $s u b$ integra and subnuda. The three forms curiosa, parcipappa and wheeleri were all described from very limited material, and all are close to, if not synonymous with, the extremely variable subintegra. All three are western in distribution, and significantly it is in the west that subintegra reaches its peak variability, in an area where a wide range of differing habitats is available to influence variation. It is also possible that these slave-makers respond in some way to the characteristics of the available slave species of Formica, which in general are more diverse in the western part of North America.

As work on the sanguinea group progressed, we solicited the aid of several of our North American colleagues with respect to problems met. While comments and material received in the ensuing exchange were often very helpful, we have been surprised at the vigor of the opposition aroused by some of our synonymic proposals. Unfortunately, the evidence for such opposed viewpoints did not match the conviction with which they were sometimes expressed. Despite requests on our part for further particulars, we have received no evidence to indicate that anything is amiss with our synonymy. We are assuming that all important relevant data have now been forwarded for our consideration in the preparation of this paper.

The couplet offered below will serve to separate workers of subnuda from those of subintegra.

A. Gula completely bare of standing hairs in all of the workers of a nest series; dorsal petiolar margin 
completely lacking hairs, or at most with one or two inconspicuous hairs less than $0.03 \mathrm{~mm}$ in length; hairs almost never present on propodeum; petiolar scale in side view nearly always thin and with a sharp crest (see fig. 7). (Boreal-alpine North America) ........................ subnuda Emery

B. At least one or two long, coarse, standing hairs normally present on the gula of a majority of the workers of a nest series; in those individuals with pronotal width of $1.0 \mathrm{~mm}$ or greater, and frequently in all of the nest members, the dorsal petiolar margin bears at least two or three hairs $0.05 \mathrm{~mm}$ or more in length; hairs frequently present on the propodeum at the junction of the dorsal and declivitous faces; petiolar scale in view usually relatively thicker and with a blunt crest (see fig. 8). (Widespread in temperate $\mathrm{N}$. America) subintegra Emery

For comments dealing with the separation of curiosa, parcipappa, and wheeleri from subintegra, see the discussions under the individual species headings below.

\section{Formica sanguinea Latreille}

Formica sanguinea Latreille, 1798, Essai Fourmis France, pp. 37-38; worker (widely distributed in temperate Eurasia).

We have had the opportunity to examine large numbers of series of this species from over most of its range. We have found it to differ with reasoriable consistency from the cognate Nearctic species subnuda in the following worker characters:

(1) The clypeal notch is much deeper in sanguinea. The section of the clypeal margin enclosing the notch appears moderately concave when the head is viewed in perfect full face (at maximum length); in subnuda it usually appears flat or feebly convex.

(2) The body hairs are longer and more abundant in sanguinea. At least four or five standing hairs project 
beyond the dorsal margin of the pronotum seen from the side; in subnuda at most three or four are visible in this view, and usually less.

(3) The head of sanguinea is always infuscated, and on the average more deeply than in subnuda, although there is some amount of overlap in the total variation of the two species.

Despite the completely allopatric distribution of sanguinea and its obvious cognate relationship to subnuda, we are treating the two forms as distinct species. The reason is that they differ by at least two discontinuous characters, while the total morphological difference is apparently greater than that separating some of the sympatric Nearctic species. Thus, in the absence of direct evidence concerning their status, reliance is placed on an arbitrary, morphological "species-standard" method in order to insure uniformity of treatment throughout the species group.

The intermediate position of sanguinea between subnuda and subintegra with respect to the pilosity and clypeal notch characters described above may represent another case of the phenomenon of "character displacement" as recently described in the genus Lasius by Wilson (1955). Our interpretation would be that subnuda remains well segregated morphologically from subintegra because it is partly sympatric with it, and as a result the two species tend to occupy ecologically different "niches." As a distinct species and the Palaearctic equivalent of subnuda, sanguinea has no such competitor, and therefore presumably converges morphologically toward subintegra in filling the adaptive vacuum which a companion species might otherwise occupy.

We have made no attempt to treat the Palaearctic "varieties" of sanguinea in the present study. Most of these are based on color differences and do not seem on cursory examination to be strong candidates for species rank. We have included in our diagnosis of sanguinea varietal material from the following several localities: Guadarrama, Spain (C. Schramm leg.; var. flavorubra 
Forel, det. W. M. Wheeler) ; Lake Sevan, Armenian S. S. R. (F. Arnoldi leg.; var. clarior Ruzsky, det. Arnoldi and B. Finzi); neighborhood of Kiev (W. Karawajew leg.; "var. clara" Karawajew, ms?) ; "Ussurigebiet", Soviet Maritime Territory (var. orientalis Ruzsky, det. Karawajew) ; Kedzovajapadj, near Vladivostok (N. Kusnezov leg.; var. clarior Ruzsky, det. Kusnezov).

Formica subnuda Emery (figs. 3, 5, 8)

Formica sanguinea rubicunda var. subnuda Emery, 1895, Zool. Jahrb. Syst., 8: 335; worker. Type locality: Yale, British Columbia.

Formica sanguinea subnuda, Wheeler, 1913, Bull. Mus. Comp. Zool. Harv., 53: 409. Creighton, 1950, Bull. Mus. Comp. Zool. Harv., 104: 469.

Formica emeryi Wheeler, 1913, Bull. Mus. Comp. Zool. Harv., 53: 419; worker, queen. Type locality: Broadmoor, Colorado Springs, Colo. NEW SYNONYMY.

This is the most boreal and widespread of the North American members of the sanguinea group. Its affinity to the Palaearctic sanguinea is evidenced by the form of the petiolar scale, pilosity, body coloration, and degree of intranidal size variation, as well as its similar ethological characteristics. The characters which separate the two species have already been presented in the section on sanguinea, above. $F$. subnuda, like $F$. sanguinea, is only facultatively a slave-maker. Even when taken, the slaves frequently form only a small percentage of the nest population, (Wheeler, "Ants,” p. 454; Creighton, 1950, p. 469).

A single worker and three queens from the emeryi type series that we have examined conform to subnuda in critical pilosity characters. Other differences advanced by past authors as diagnostic for emeryi have proven to be worthless. To avoid future confusion these are discussed in some detail below.

(1) Emeryi has been distinguished from subnuda (by Creighton) on the contention that in the largest workers the eyes extend to the margin of the head seen in full 
face. As previously noted, this is a character subject to strong allometric variation. The subnuda types we have examined in the same size class as the emeryi syntypes (head widths $1.41-1.64 \mathrm{~mm}$ ) exhibit the same head shape and eye placement, and this also holds for other subnuda series.

(2) Wheeler and Creighton both have distinguished emeryi from subintegra (= pergandei) by the presence in emeryi of a shallow transverse groove on the dorsal propodeal face of the worker. In this case the wrong pair of species was being compared, but the character must also be considered with reference to subnuda. Of the four subnuda syntypes we have examined, three possess the character and one lacks it. Other subnuda and subintegra series show the same strong intrandidal variation, and we are of the opinion that the propodeal impression is either an ecophenotypic character or else an artifact produced by warping when the specimens were first dried out. In any case, it is not diagnostic.

(3) The genal borders of the emeryi syntype are nearly straight, and where they meet the curved occipital border near the lower margin of the eye a weak concavity is produced. This is not so common a feature of subnuda, but is nevertheless within the normal range of variation for the species. One specimen of a series from Magnolia, Mass., shows the "emeryi" contour on one side and the typical subnuda contour on the other.

(4) The emeryi worker and queen syntypes actually differ the most from average subnuda in a character not mentioned by previous authors. The petiolar scale in side view is unusually thick for subnuda, approaching the usual subintegra condition, but even this is still within the range of continuous variation of subnuda as we conceive of that species.

$F$. subnuda definitely has a more boreal distribution than does $F$. subintegra, though the ranges of the two species come into close contact and even overlap in regions such as eastern Massachusetts, part of Michigan, and in 
widespread areas in the Rocky Mountains. The northern distribution brings subnuda into broad contact with Formica neorufibarbis, which frequently is pressed into slavery.

\section{Formica subintegra Emery (figs. 1, 7)}

Formica sanguinea var. subintegra Emery, 1893, Zool. Jahrb. Syst., 7: 648; worker. Type locality: District of Columbia.

Formica subintegra Creighton, 1950, op. cit., p. 470.

Formica pergandei Emery, 1893, op. cit., pp. 646-647; worker. Type locality: District of Columbia. NEW SYNONYMY.

Formica sanguinea rubicunda Emery, 1893, op. cit., pp. 647-648; worker, queen. Type locality: Pennsylvania. NEW SYNONYMY.

Formica rubicunda, Creighton, 1950, op. cit., p. 468.

Formica sanguinea puberula Emery, 1893, op. cit., p. 648; worker. Type locality: Hill City, South Dakota. NEw SYNONYMY.

Formica puberula, Creighton, 1950, op. cit., p. 468.

Formica sanguinea rubicunda var. sublucida Wheeler, 1913, Bull. Mus. Comp. Zool. Harv., 53: 408; worker. Type locality: Stony Brook Reservation, near Boston, Mass. NEW SYNONYMY.

Formica sublucida, Creighton, 1950, op. cit., p. 471.

Formica sanguinea subintegra var. gilvescens Wheeler, 1913, op. cit., pp. 412-413; worker. Type locality: Tuckahoe, New York.

The involved synonymy under subintegra has been the principal source of difficulty in the taxonomy of the sanguinea group. Myrmecologists in recent years have wasted untold amounts of time trying to distinguish species, the types of which represent nothing more than trivial infraspecific variants. The characters on which these species 
were based have been greatly exaggerated by both the original describers and subsequent reviewers.

Rubicunda is probably the most often used of the names considered herein as junior synonyms. Several characters have been advanced at different times and by different authors in an attempt to separate this form. The merits of each are discussed below.

(1) Rubicunda is said to have a darker body color; the gaster is piceous and the rest of the body "blood red", while in subintegra (the type series included) the gaster is medium brown and the remainder of the body yellowish red. Even in his original description, Emery made note of a series intermediate in color to subintegra. Fresh series in the Museum of Comparative Zoology grade through in this character; also, it has been our impression in the field that color is not reliable.

(2) The head has been considered more trapezoidal in rubicunda. We find that head shape shows great variation both intranidally, through allometry, and internidally, through different grades of allometry. We have been unable to separate two forms in any given size class on the basis of this character.

(3) Rubicunda has been considered to be distinguished by an emarginate dorsal petiolar border, opposed to an non-emarginate condition in subintegra. A glance at a small number of series is sufficient to show that this character grades through completely.

A syntype of pergandei in the Museum of Comparative Zoology appears in every aspect to be only a small but otherwise normal worker of subintegra. In full face view, a small space is left between the eye and the margin of the head, contrary to the key character presented by Creighton. But even if the eye extended to or beyond the margin, this would still not exceed the range of variation of subintegra, which is highly variable in head shape (see under curiosa).

Puberula, according to the diagnoses of both Wheeler and Creighton, is marked by the presence of raised pube- 
scence on the scape, especially (according to Creighton) on the inner surface near the tip. The most extreme series we have examined, from Pullman, Wash. (W. M. Mann), has no more than four or five hairs raised at all strikingly from the surface along any single edge of the scape, and none of these makes an angle of more than $45^{\circ}$. Other western series show every gradation from this extreme to the typical, completely "smooth" subintegra condition. An intermediate pilosity has been encountered also in a series from Rogers City, Presque Isle Co., Mich. (P. B. Kannowski), but otherwise the puberula variant is mostly limited to the western United States.

Sublucida was erected by Wheeler for a single series, which he considered to have a distinctively smooth and shining body surface. Examination has shown that this series is really well within the normal range of variation of subintegra, and in fact is not far from average for that species. Wheeler's inability to recognize his own variety was revealed when he later inadvertently added a large part of the unlabelled sublucida type series to the subintegra section of his collection.

Perhaps the most extensive variation shown by subintegra is in quantity and length of body pilosity. At one extreme, exemplified by the type series, numerous hairs are present on the pronotum and mesonotum, at the junction of the basal and declivitous faces of the propodeum, and along the dorsal crest of the petiole. The pronotal hairs are especially abundant, fairly long and sinuous, and form a characteristic pattern, the anterior ones bending posteriorly and the posterior ones bending anteriorly, so that those at the very center often seem in side view to touch or cross at the tips. At the other extreme, recognized by Wheeler in his variety gilvescens, only a few scattered stubby hairs are present on the pronotum, and the mesonotum, propodeum, and petiolar crest are completely bare. The "typical" subintegra tends to have longer hairs throughout, e. g. the longest on the first gastric tergite (exclusive of the extreme posterior strip) may be $0.20 \mathrm{~mm}$ or more, while in the "gilvescens" extreme of 
equivalent size the longest may not exceed $0.06 \mathrm{~mm}$.

Mr. P. B. Kannowski has recently expressed the opinion to us (in litt.) that what we call "the gilvescens form" perhaps represents a distinct species distinguished by the following characters supplemental to pilosity: occiput more rounded, petiole blunter and usually with an emarginate dorsal border, gaster usually lighter in color. We have examined in detail 54 nest series from all over the eastern United States (excluding available western samples, which may be complicated by the presence of possible sibling species such as curiosa and wheeleri). We have noted a weak tendency, with many exceptions, toward correlation in Kannowski's characters, but we have not been able to detect significant bimodality in any character or character combination.

$F$. subintegra appears to be an obligatory slave-maker, and the proportion of slaves to subintegra workers is normally higher than the corresponding ratio in subnuda nests. Subintegra occurs largely within the United States, usually at lower latitudes and altitudes than subnuda. It takes a great variety of slaves, including members of the fusca, pallidefulva and neogagates groups, and it can occupy a wide range of habitats from mesic even to somewhat xeric.

\section{Formica curiosa Creighton (fig. 2)}

Formica curiosa Creighton, 1935, Amer. Mus. Novitates, no. 773 , pp. 5-8; worker, queen. Type locality: Lake McGregor, near Kalispell, Montana.

This species is presumed distinguishable by the queen, which is concolorous yellowish red. A careful examination of part of the type series has failed to reveal any characters which will surely separate the worker caste of curiosa from the worker caste of subintegra as we broadly conceive of it here. We have noted several character trends, however, which may prove significant as more collections are made in the future.

(1) The placement of the eye as described by Creighton may have some merit as a character, and we have attempted to refine it as follows: in the six curiosa syntypes 
we have examined (head width 1.08-1.32 $\mathrm{mm}$ ) the eyes extend prominently beyond the margins of the head seen in full face. In the majority of subintegra cabinet series, few or none of the workers range below $1.32 \mathrm{~mm}$ in head width. In those that do, the shape of the head and placement of the eyes are highly variable. Some approach the curiosa condition; e. g. Broadmoor, Colo. (W. M. Wheeler) ; Alamogordo, N. Mex. (G. v. Krockow) ; Bronxville, N. Y. (Wheeler). In others, the eyes do not approach the lateral margins; e. g. Pullman, Wash. (W. M. Mann) ; Breckenridge, Colo. (P. J. Schmitt) ; Tesuque Canyon, Hyde Park, N. Mex. (A. C. Cole); Manzanares, N. Mex. (M. Cooper). At least one series is intermediate: Manitou, Colo. (Wheeler) ; associated queens here are typical subintegra and do not approach the curiosa color character. In general, variation is primarily internidal, with allometric trends within single nest series remaining constant. The "curiosa" head shape may be more common in western series of subintegra - at least the tendency for the production of smaller workers of the curiosa size class seems to be stronger.

(2) Worker series from Culbertson, Mont. (E. O. Wilson) and Twin Falls, Ida. (Cole), unaccompanied by queens and therefore not definitely determinable, are so similar in pilosity and minor-worker head shape to the curiosa types that they have been tentatively associated with this species. If correctly determined, then they may provide the additional diagnostic character: larger workers (head width 1.45-1.65 $\mathrm{mm}$ ) are present and differ from $s u b$ integra workers of equivalent size by having heads proportionately more massive and with a slightly more quadrate frontal outline (figs. 1,2).

(3) The body pilosity of the curiosa types and Culbertson and Twin Falls series is very long and abundant, with numerous hairs on the mesonotum, but still within the extreme range of variation of verified subintegra.

(4) The first gastric tergite, exclusive of the extreme posterior strip, is yellowish brown in color and contrasts with the remainder of the gaster in the larger curiosa 
types and Culbertson workers, but resembles the subintegra condition in the Twin Falls series.

(5) All three series have relatively short antennal scapes consistent with the western subintegra population.

Formica parcipappa Cole

Formica parcipappa Cole, 1946, Ann. Ent. Soc. Amer., 39: 616; worker. Type locality: Nampa, Idaho.

The diagnostic character lies with the reddish yellow gaster of the worker, little or no darker than the alitrunk. We can find no structural characters that will separate the meager known sample of parcipappa from subintegra, and the light color will have to be the basis upon which this species uneasily rests. The "gilvescens" form of subintegra is frequently nearly as light and as close to concolorous as the parcipappa types, but the extent to which such coloration is due to tenerality or cabinet fading remains unknown. Dr. Cole (in litt.) assures us that the parcipappa types were noted as near their present striking hue when collected alive.

The variable lightening of the anterior gastric segments in some western series of curiosa (see above) suggests a condition intergradient between the gastric pigmentations of bicolorous subintegra and concolorous parcipappa. This species will remain doubtful at least until additional material is studied.

\section{Formica wheeleri Creighton}

Formica wheeleri Creighton, 1935, Amer. Mus. Novitates, no. 773, pp. 1-5; worker, queen. Type locality: Warner Ranger Station, La Sal Mountains, Utah, 9500 feet.

This species is supposed to be separable by the dark brownish tone of the head and alitrunk of the queen, and by the generally reduced size of this caste; the head is only slightly larger than that of the largest workers. No characters have been discovered that will surely separate the worker caste of wheeleri from that of subintegra. Workers in the type series possess very deep clypeal notches and show light cephalic infuscation, but both 
features are within the extremes of the range of variation of verified subintegra. We have tentatively associated with wheeleri a series from Madison Junction, Yellowstone Park, Wyoming, 6800 feet (E. O. Wilson). The queens are smaller than eastern subintegra at our disposal and appear darker despite their teneral condition. The workers differ from the wheeleri types by the possession of a shallower clypeal notch and "puberula" pilosity type (see under subintegra). A queen collected with workers by A. C. Cole at Dailey Canyon, Beulah, New Mexico, 8000 feet, is intermediate between the Yellowstone series and eastern subintegra in size and color. We have not been able to see a syntype queen of wheeleri, but judging from Creighton's description alone, the gap between wheeleri and subintegra appears to be filled by the Yellowstone and Dailey Canyon series. Future collecting in the Rockies and Great Basin may reveal that wheeleri is nothing more than one of the western variants of subintegra.

\section{The Obtusopilosa Complex of the Neggagates Group}

In the light of their new association with $F$. neogagates and relatives, the obtusopilosa group species must now all be re-evaluated. It is possible that some additional synonymy previously obscured by the false RaptiformicaProformica dichotomy will be established when the neogagates group meets its first comprehensive revision. Such revision is not attempted here.

\section{Formica bradleyi Wheeler}

Formica bradleyi Wheeler, 1913, Bull. Mus. Comp. Zool. Harv., 53: 423-425; worker, male. Type locality: Georgetown, Colorado.

Formica (Proformica) neogagates var. morbida Wheeler, 1913, ibid., pp. 538-539; worker, queen. Type locality: Lenox, Iowa. Synonymized under $F$. neogagates Emery by Creighton, 1950, p. 459. NEW SyNONYMY.

Syntypes of bradleyi and morbida in the Museum of Comparative Zoology have been compared, and are closely similar, corroborating Dr. Buren's findings. F. bradleyi 
differs from neogagates in its much lighter color and denser and longer body pilosity.

\section{Formica manni Wheeler}

Formica manni Wheeler, 1913, Bull. Mus. Comp. Zool. Harv., 53: 420-421; worker, queen. Type locality: Kiona, Washington.

Formica oregonensis Cole, 1938, Amer. Midl. Nat., 20: 368-369; worker. Type locality: Pendleton, Oregon. NEW SYNONYMY.

Four paratypes of oregonensis in the Museum of Compartive Zoology are identical to the type series of manni in nearly all characters studied. Only the two characters treated below seem worthy of further discussion.

(1) Creighton (1950) states that the largest workers of oregonensis exceed the largest of manni in size. However, the M. C. Z. oregonensis paratypes show a head width range of 1.05-1.27 $\mathrm{mm}$, while the M. C. Z. manni type series ranges $0.97-1.29 \mathrm{~mm}$. There is no indication of a significant mean difference between these two samples.

(2) The alitrunk and head of the oregonensis types are dark brown, while those of the manni types are clear yellowish red. This difference apparently reflects geographic variation, i. e., a tendency to darken southward. Series from Wenatchee and Wapato, Wash. (Mann) are similar to the manni types in coloration. Series from Ellensburg, Wash. (Mann), Twin Falls, Ida. (Cole), and Hammett, Ida. (E. O. Wilson) exhibit varying degrees of intermediate infuscation. A single queen from Owens Lake, Calif. (H. F. Wickham) has a slightly darker altitrunk than the manni gynetype, but an even lighter head.

The extreme coloration of the oregonensis types may be a consequence, either genetic or ecophenotypic, of the unusual environment in which they were collected. Cole found them on an herb in an alpine meadow above timberline. The Washington manni (Wheeler, 1913) and the series from Hammett were taken under radically different conditions at low elevations in desert habitats. 
Manni may be following Gloger's rule, tending to darken in a cooler, moister climate.

\section{Formica obtusopilosa Emery}

Formica obtusopilosa Emery, 1893, Zool. Jahrb. Syst., 7: 648-649; worker. Type locality: New Mexico.

Formica munda var. alticola Wheeler, 1917, Proc. Amer. Acad. Arts Sci. Boston, 52 : 534; worker. Type locality: Jefferson Co., Colo., 9500 feet. NEW SynONymy.

Formica obtusopilosa alticola Creighton, 1950, Bull. Mus. Comp. Zool. Harv., 104: 466.

Wheeler's variety alticola was based on workers differing from typical obtusopilosa $(=$ munda) only by a darker body color, a character of demonstrably little taxonomic value in other "sanguinea group" members. Creighton retained alticola because of the possibility that it might represent a geographic altitudinal variant. We are inclined to discount even this possibility now, in view of the fact that a collection of workers as dark as the alticola types has recently been made in scrub desert at 6000 feet near Junction, Piute Co., Utah (E. O. Wilson). The position of obtusopilosa as to species group is at present very uncertain, and may not be settled until males are studied.

Formica perpilosa Wheeler (figs. 4, 6)

Formica fusca subpolita var. perpilosa Wheeler, 1907, Mem. Revist. Soc. Ant. Alzate, 17: 141; worker. Type locality: Canyon City, Colo.

Formica perpilosa Wheeler, 1913, Bull. Mus. Comp. Zool. Harv., 53: 421.

\section{Acknowledgements}

After the first draft of this paper had been prepared, we were privileged to examine a near-finished manuscript by Dr. W. F. Buren dealing broadly with the subject of group classification within the genus Formica. The correspondence between Buren's and our ideas on this subject are frequently close and detailed (within the scope of 
our own present paper), and most of the morphological observations bearing on species-group affinities are identical, even though independently accomplished. Dr. Buren has graciously deferred to us in the mention of a few points discovered by himself where these are necessary to a clear understanding of the group affinities of the species treated below, and for this we are most grateful. It is inconvenient for us to indicate in the text all points that should be credited in whole or part to Buren's original work, but it can be emphasized that his contribution was indeed an important one. Treatment of species within the sanguinea group, however, is entirely original with us.

We have also consulted for purposes of this study Dr. A. C. Cole, Mr. P. B. Kannowski, and Dr. Mary Talbot (all of whom also furnished important series), Dr. W. S. Creighton, Dr. R. E. Gregg and Dr. M. R. Smith. We thank these workers for their criticisms and information.

Creighton, W. S.

\section{Literature Cited}

1950. The ants of North America. Bull. Mus. Comp. Zool. Harv., 104: 1-585, 57 pls.

WHEELER, W. M.

1913. A revision of the ants of the genus Formica (Linné) Mayr. Bull. Mus. Comp. Zool. Harv., 53: 379-565.

WILSON, E. O.

1955. A monographic revision of the ant genus Lasius. Bull. Mus. Comp. Zool. Harv., 113: 1-201. 

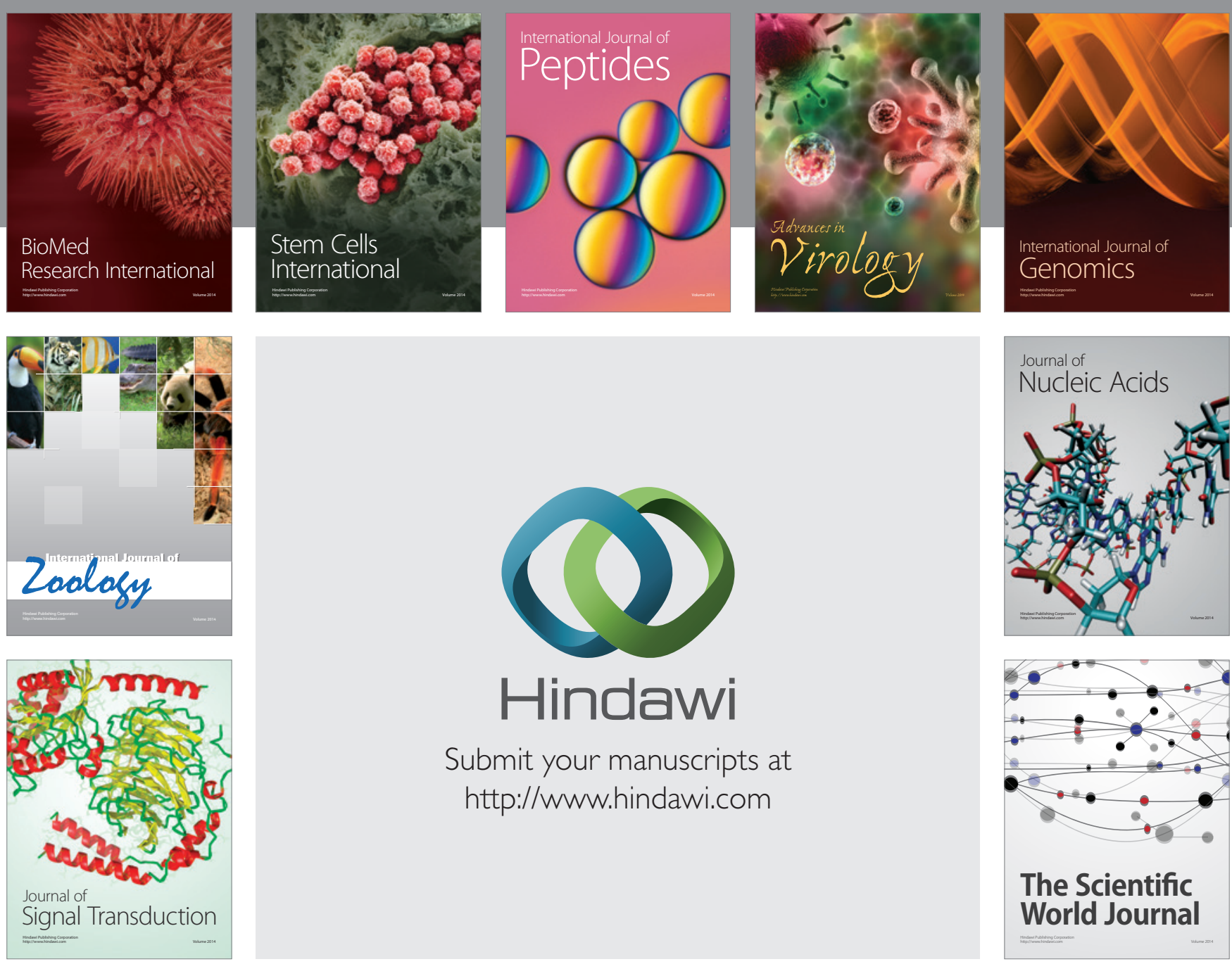

Submit your manuscripts at

http://www.hindawi.com
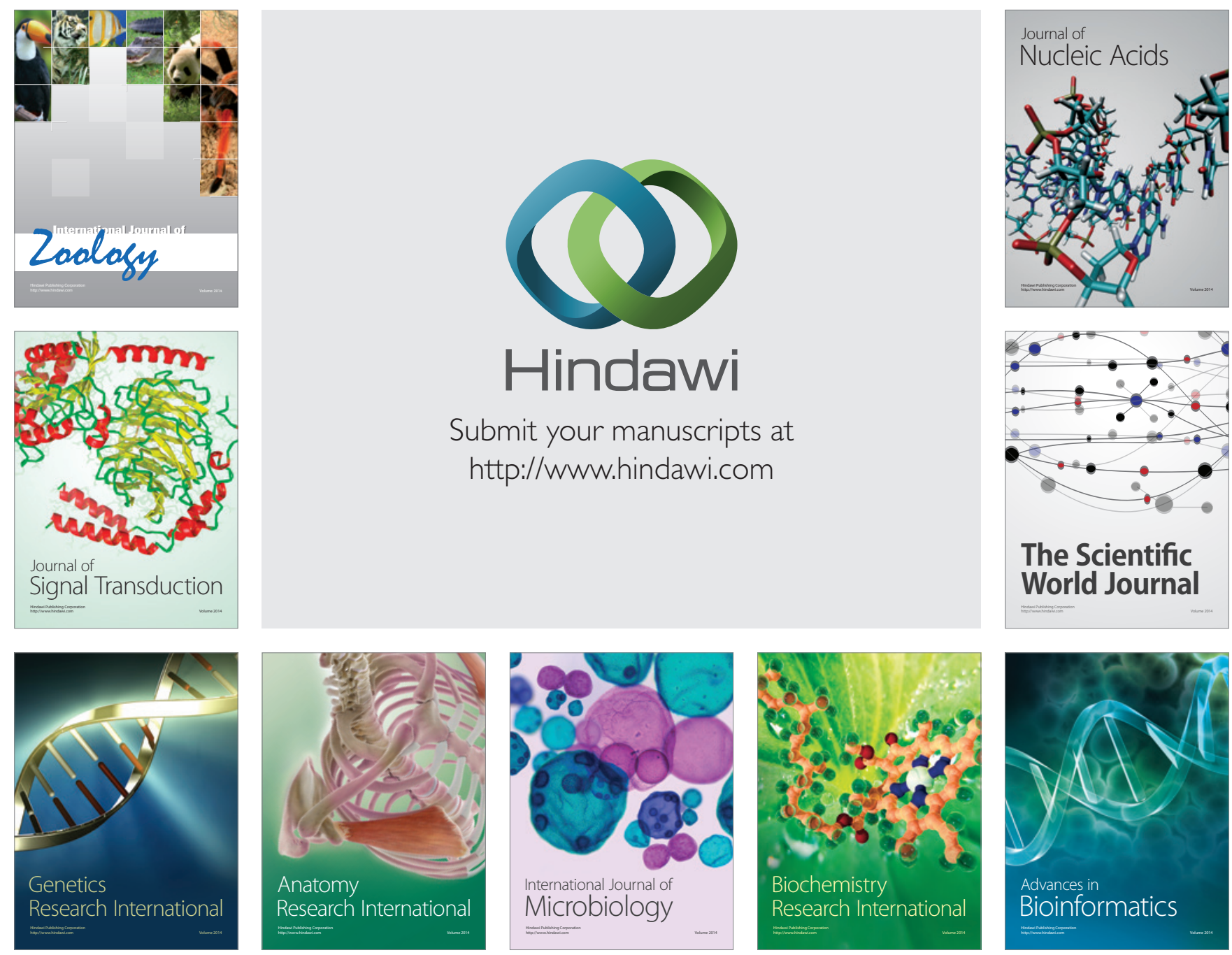

The Scientific World Journal
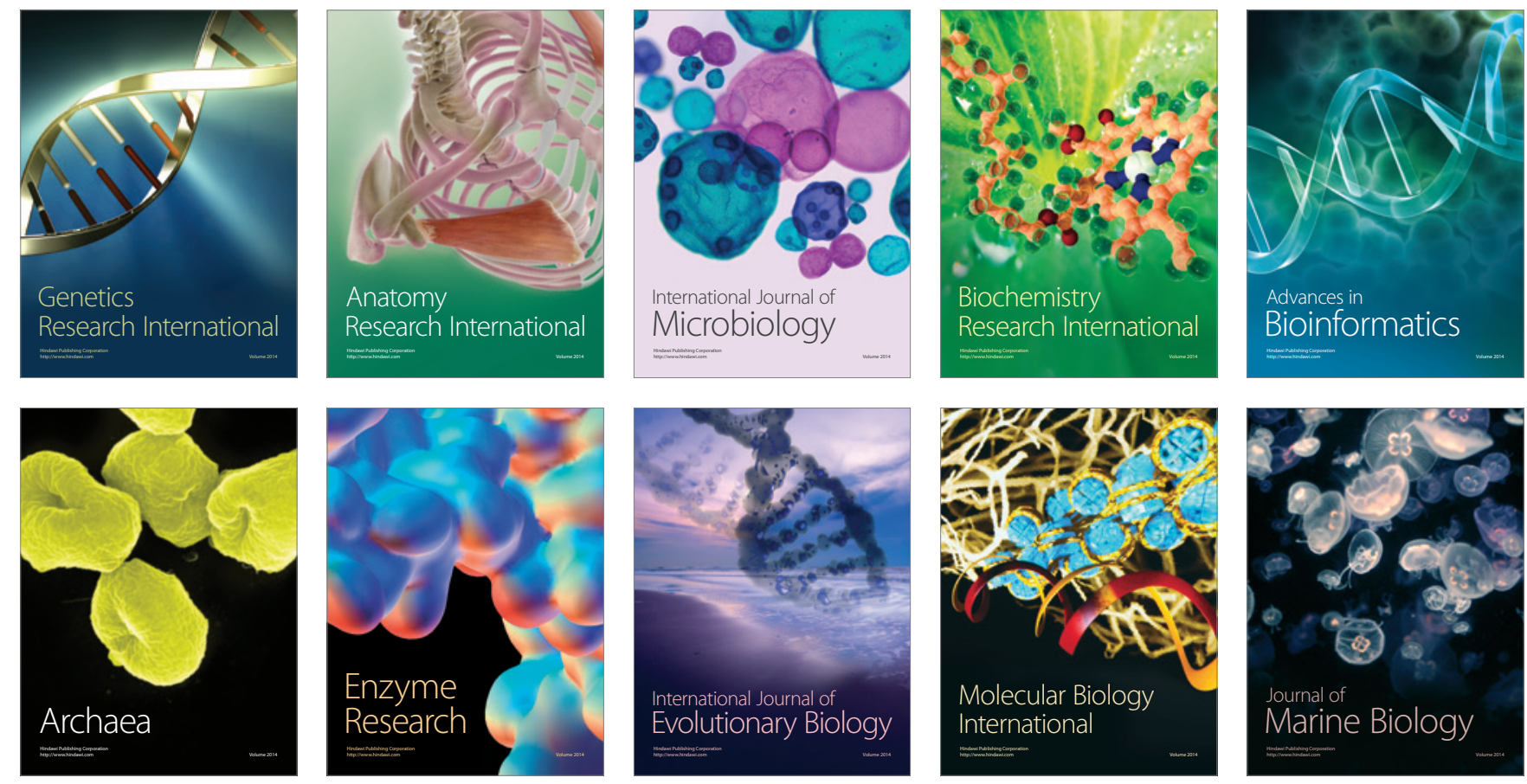